\title{
First report of Rhizoctonia solani AG 4 HG-III causing root rot of pepper in Kyrgyzstan
}

\author{
Ismail Erper ${ }^{1,2}$ (I) $\cdot$ Goksel Özer $^{3} \cdot$ Sezim Zholdoshbekova ${ }^{1} \cdot$ Elif Yildirim $^{2} \cdot$ Muharrem Turkkan $^{4}$
}

Received: 17 May 2020 / Accepted: 9 October 2020 / Published online: 21 October 2020

(C) Società Italiana di Patologia Vegetale (S.I.Pa.V.) 2020

Keywords Pepper $\cdot$ Rhizoctonia solani $\cdot$ ITS region

Pepper (Capsicum annuum L.) is one of the important vegetable species grown in Kyrgyzstan. In 2019, approximately $4 \%$ of mature pepper plants showed root rot symptoms in three fields located in Bishkek city. Symptomatic segments excised from necrotic lesions on root were surface sterilized with $1 \% \mathrm{NaOCl}$, washed twice in sterilized water, blotted on sterile filter paper, and plated on Potato Dextrose Agar (PDA) amended with streptomycin sulfate. Hyphal tips were transferred to new plates containing PDA to obtain pure cultures, after two-day incubation period at $25{ }^{\circ} \mathrm{C}$. Three isolates were selected to identify from morphologically similar fungal colonies. The young hyphae exhibited characteristics of Rhizoctonia spp.; the presence of relatively broad septate hyphae, acute angular branching near the distal septum, and multinucleated cells (4 to 8 nuclei for per cell). These morphological features were consistent with those of Rhizoctonia solani Kühn. The internal transcribed spacer (ITS) region of rDNA of three isolates was amplified and sequenced using ITS1/ITS4 primers to determine anastomosis group (AG) of the isolates. BLASTn analysis of the $724 \mathrm{bp}$ products

Ismail Erper

ismail.erper@manas.edu.kg; ismailer@omu.edu.tr

1 Department of Plant Protection, Faculty of Agriculture, Kyrgyz Turkish Manas University, 720044 Bishkek, Kyrgyzstan

2 Department of Plant Protection, Faculty of Agriculture, Ondokuz Mayis University, Atakum, 55139 Samsun, Turkey

3 Department of Plant Protection, Faculty of Agriculture, Bolu Abant Izzet Baysal University, 14030 Bolu, Turkey

4 Department of Plant Protection, Faculty of Agriculture, Ordu University, 52200 Ordu, Turkey (accession Nos. MT460102-460104) were identical and showed $100 \%$ nucleotide similarity with those of the sequence of $R$. solani AG 4 HG-III (AF354076). To confirm pathogenicity, the roots of six-week-old seedlings of pepper cv. Dila were inoculated with isolate "4 A-4" infested wheat kernels, and the trials carried out in six replications (Türkkan et al. 2018). Typical symptoms appeared on all inoculated seedlings, similar to those observed originally in the field, two weeks after inoculation. No symptoms were observed on control seedlings treated with sterile wheat kernels. The pathogen was consistently isolated from the inoculated seedlings onto PDA, thereby confirming Koch's postulates. To our knowledge, this is the first report of Rhizoctonia solani AG 4 HG-III causing root rot of pepper in Kyrgyzstan (Farr and Rossman 2020).

\section{Compliance with ethical standards}

Conflict of interest The authors declare that they have no conflict of interest.

Research involving human participants and/or animals The authors declare that no human participants and animals were involved in this study.

Informed consent This manuscript is new and not being considered elsewhere. All authors have approved the submission of this manuscript.

\section{References}

Farr DF, Rossman AY (2020) Fungal Databases, U.S. National Fungus Collections, ARS, USDA. https:/nt.ars-grin.gov/fungaldatabases/. Accessed 15 May 2020

Türkkan M, Erper I, Kılıçoğlu M, Yazıcıoğlu E, Özcan M (2018) Characterization and pathogenicity of Rhizoctonia spp. isolated from kiwifruit in the Middle and Eastern Black Sea region of Turkey. J Phytopathol 166:761-774 